\title{
Assessment of Thermoplastic Weldability Using the Deformation Technique
}

\section{A new technique to join the polymer through the Y-shape die channel was developed}

\author{
BY P. KUMAR AND S. S. PANDA
}

\begin{abstract}
The joining of similar/dissimilar materials by using conventional and nonconventional techniques is a challenging task to produce cost-effective joints without overweighing the product. Traditionally, adhesive welding is the preferred technique used to join polymers at the cost of increase in product weight. The use of nonconventional techniques in welding polymers is limited due to an expensive source of energy. However, all of these techniques have limited applications for the joining of polymers. To overcome this limitation, constant efforts are given to develop a new technique to join the polymer through the Y-shape die channel. The Yshape die channel is the reliable method to join two similar natures of polymers without the use of additive materials, hence product overweight can be avoided. The joint employed through the preheated die channel at $150^{\circ} \mathrm{C}$ and developed back pressure cause proper blending between the polymers. The reason for the development of back pressure is the nature of joint interface with exploring the scope of metal forming operation such as extrusion and equal channel angular pressing (ECAP) into a new joining procedure. Channel design, joining procedures, dynamic mechanical analysis (DMA), and $x$-ray diffraction (XRD) of the joints were used to assess the weldability of polymers.
\end{abstract}

\section{KEYWORDS}

- Y-Shape • Extrusion • Equal Channel Angular Pressing

- Polymer • Dynamic Mechanical Analysis • X-Ray Diffraction

\section{Introduction}

Several deformation techniques to produce lightweight material with higher mechanical properties have significant applications as compared to other manufacturing processes (Ref. 1). Polymers replace metals and its alloys from differ- ent applications due to the benefits accrued, such as low weight to strength ratio, lower manufacturing costs, corrosion resistance, and design flexibility (Ref. 2). Parts made with a combination of similar/dissimilar materials, such as metal-metal, polymer-polymer, and metal-polymer, are in high demand. The aim of joining two materials is to improve the product design and their mechanical properties to utilize it in an efficient and functional manner based on the type of applications. However, optimal mechanical performance of a low-weight material with cost-effective joining is a challenging task for any structural application (Ref. 3).

Nonconventional energy sources such as microwaves, high-speed lasers, and solar energy are different methods for joining the polymers. Radiation interaction between the polymers causes microwave to yield a better quality of joint, but the product is expensive (Ref. 4). High-speed laser welding is used to weld polymer as well as metal, but product weight increases due to the addition of additive to increase the heat absorption capacity of polymer/metal (Ref. 4). Another technique to join the polymers by solar energy concentrator has irregular power supply and is limited to daytime only (Ref. 5).

Conventional methods, such as mechanical fastening, hot plate welding, hot gas welding, and adhesive bonding, are frequently used for joining polymers (Refs. 6, 7). In the joining of polymers and metals, authors recommend adhesive joining, which is more reliable and flexible compared to mechanical joining (Ref. 8). Bartczak et al. (Ref. 9) observed that load-bearing capacity is higher in the adhesive joint as compared to spot welding. Hot plate welding is another popular joining technique used to achieve strong weld strength in thermoplastic composite (Ref. 10). Polymer surface in hot plate joining techniques is diffused when the part is subjected to high compressive load. Stress concentration due to spot welding (Ref. 10), a requirement of extensive surface preparation and heavy weight due to additive materials (Ref. 11), and harmful environmental emissions during chemical 
A

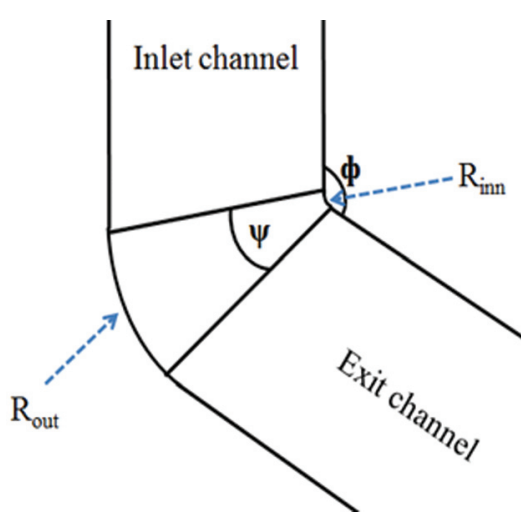

B

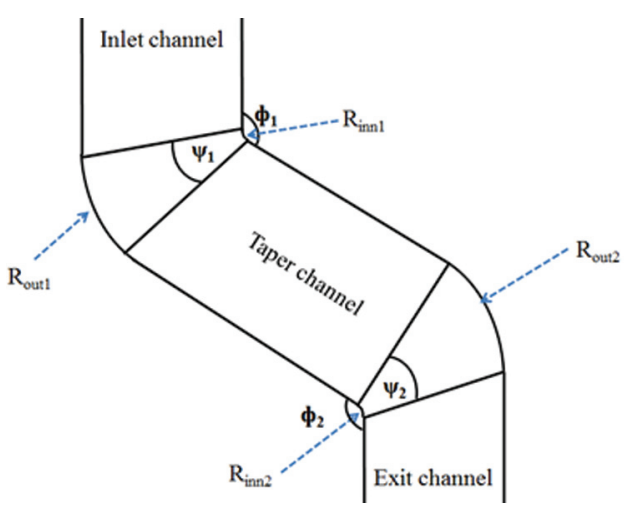

Fig. 1-Schematic of ECAP channel: A - One turn (L-shape); B - two turn (S-shape).
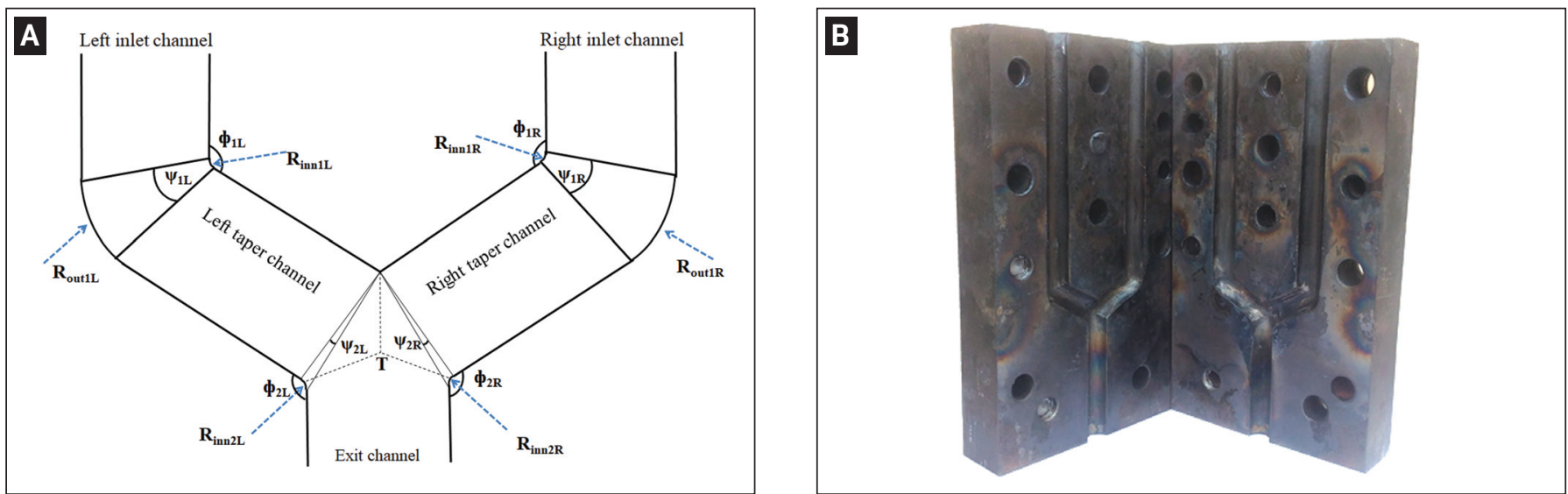

Fig. 2 - Y-shape die channel: A - Channel schematic; B - actual die design.

reactions (Ref. 12) are certain limitation of the mechanical fastening and joining technique.

Another conventional technique to join the polymers is friction stir welding (Ref. 13), but the application of this technique is limited in polymers joining because of the sticking behavior of tools and polymers. To retain softened polymers in the welded zone, Bozkurt used optimization techniques over tool rotation speed, tool transverse speed, and tool tilt angle to achieve the sound strength of the weld (Ref. 14). No other techniques are available to avoid the void generated during the joining of polymers; however, modified solid state welding can supplement this issue with an application of external pressure over the welded region.

Kumar and Panda (Ref. 15) recently developed a Y-shape die channel to join the similar nature of Anulon-114 polyamide rods. As a part of a conventional technique, the Yshape die channel works on the deformation technique principle where polymers passed through the Y-shape channel in a preheated die condition at $2 / 3$ of polymers melting point. The softened polymers diffused when it passed through a reduced die section of the Y-shape channel. Pressure developed in the reduced die section minimizes the void without outweighing the weight of the product. Such additive-free polymer joints have higher hardness in comparison to base polymer.

One-turn equal channel angular pressing (ECAP) (L-shape) works on severe plastic deformation (SPD) to refine the grain size without changing its initial cross-sectional area of speci- men as in Fig. 1A (Ref. 16). A mathematical relation was proposed by Kumar and Panda to find a maximum equivalent plastic strain, as given in Equation 1 (Ref. 17). To achieve higher equivalent plastic strain, the billet taken from the exit channel is reused a number of times by following different routes of rotation (Ref. 18). In each number of passes, the billet gets further refined, resulting in an increase in punch load. Surface fractures and extensive punch load over specimen are major drawbacks of the processes because this method is still under consideration for laboratory tests (Ref. 19). To prevent surface fracture and the rise of punch load, die preheating can be employed in the process, but it deteriorates the mechanical properties of the billet (Ref. 20). Similarly in another work, it has been observed that back pressure is utilized in the process to minimize surface fracture, but it fails to reduce the punch load (Ref. 21). Kumar and Panda used a two-turn (S-shape) ECAP channel to minimize the number of passes and volumetric loss in a single press as shown in Fig. 1B (Ref. 22). Previous researchers observed that channel geometry, selection of materials, material dimensions, and working conditions are important factors that influence the punch load.

$$
\varepsilon=\frac{N}{\sqrt{3}}\left\{2 \cot \left(\frac{\phi+\psi}{2}\right)+\psi \operatorname{cosec}\left(\frac{\phi+\psi}{2}\right)\right\}
$$

where $\mathrm{N}$ is the number of passes, $\phi$ is the channel angle, and $\psi$ is the corner angle. 


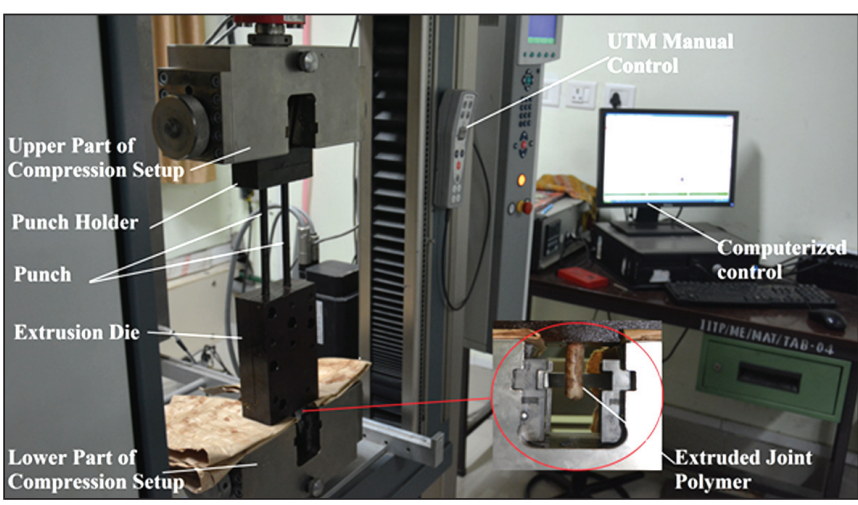

Fig. 3 - Experimental procedure to extrude the polymer.

Several authors have reported that the application of high pressure in extruding the polymer raises the glass transaction temperature in the order of $0.02^{\circ} \mathrm{C} / \mathrm{kg} / \mathrm{cm}^{2}$ (Refs. 23, 24). The objective of this work is to explore the metal forming operation in the joining procedure by using the effect of both die preheating and developed back pressure. Moreover, the effect of die preheating in response of storage modulus, loss factor, loss tangent, and crystal parameter observed for extruded polymer is compared with base polymer. This paper discusses the design guideline of the Y-shape die channel, materials joining procedure, and their properties characterization.

\section{Materials and Methods}

\section{Design of Die Channel}

Design of the Y-shape die channel to join the polymer was based on the die schematic of ECAP channel. Details of die fabrication and its working procedure were as followed:

In design, one-turn ECAP channel has two abrupt angles known as channel angle $(\phi)$ and corner angle $(\psi)$ as shown in Fig. 1A. Channel and corner angles at bend enable the billet to move forward by imposing a large plastic strain when passed through the inner die radii $\left(R_{\text {inn }}\right)$ and outer die radii $\left(R_{\text {out }}\right)$. In two-turn ECAP channel, each end of the taper channel intersected with two different channels known as inlet channel and exit channel as shown in Fig. 1B. The billet sheared at the first die turn and continuously flowed through the taper channel and then exited.

Developed Y-shape die channel as shown in Fig. 2A and B is the embodiment of two similar and circular two-turn ECAP channels as shown in Fig. 1B (Ref. 25). In die design, the Y embodies two inlet channels, two taper channels, and one common exit channel as shown in Fig. 2A and B. Due to the design symmetricity, channel is marked as left and right for the nomenclature of geometry as specified in Fig. 2A. Offset distance between both inlet channels resulted in the intersection of taper channel having a common exit channel. The axial point of intersection between taper channels and common exit channel is termed as tri-junction ( $\mathrm{T})$. In both symmetric channels, channel angle $\left(\phi_{1 \mathrm{~L}}, \phi_{2 \mathrm{~L}}, \phi_{1 \mathrm{R}}, \phi_{2 \mathrm{R}}\right)$, corner angle $\left(\psi_{1 \mathrm{~L}}\right.$, $\left.\psi_{1 \mathrm{R}}\right)$, inner die radii $\left(\mathrm{R}_{\text {inn1L }}, \mathrm{R}_{\mathrm{inn} 2 \mathrm{~L}}, \mathrm{R}_{\mathrm{inn} 1 \mathrm{R}}, \mathrm{R}_{\mathrm{inn} 2 \mathrm{R}}\right)$, and outer die radii $\left(R_{\text {out1L }}, R_{\text {out } 2 R}\right)$ were constant at each die turn. The $Y$-shape die channel as observed in Fig. 2A and B has a circular cross
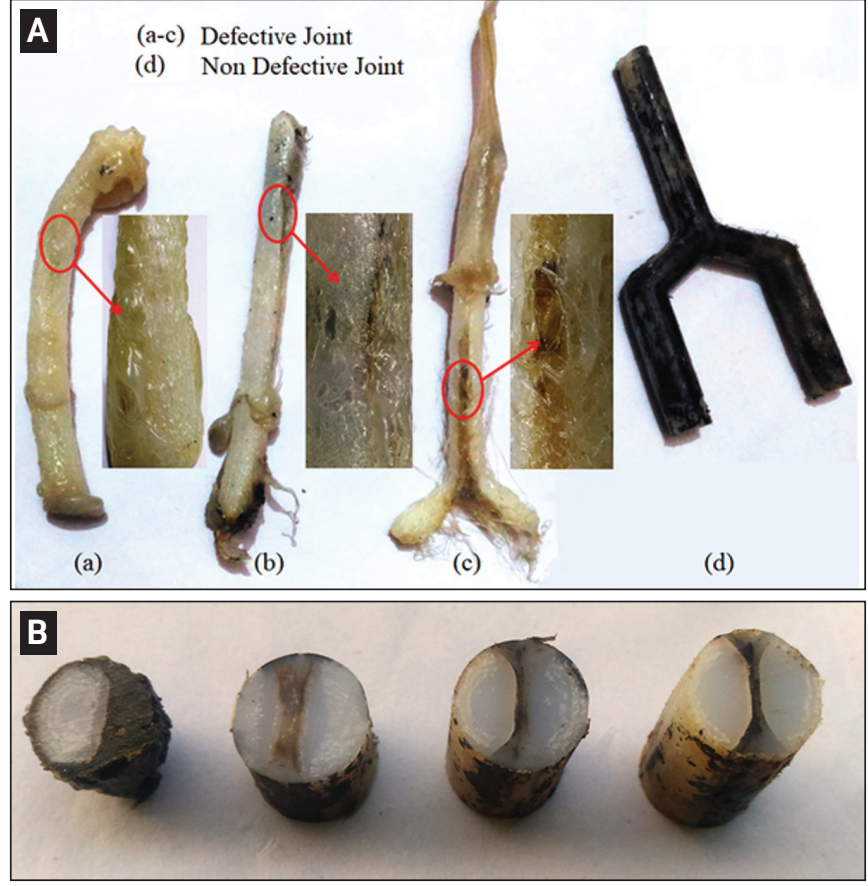

Fig. 4 - Polymers through preheated die at the following: A - Joint polymers; $B$ - concave structure.

section of $12 \mathrm{~mm}$ diameter, 120-deg channel angle, 20-deg corner angle, 2-mm internal die radii, and 5-mm outer die radii. Material from two different inlet channels to the common exit channel was merged at tri-junction where the presence of the corner angle $\left(\psi_{2 \mathrm{~L}}, \psi_{2 \mathrm{R}}\right)$ and outer die radii $\left(\mathrm{R}_{\text {out } 2 \mathrm{~L}}\right.$, $R_{\text {out } 2 R}$ ) was ineffective in comparison to the first die turn. For easier processing of materials, the die was split into two equal parts. To control eccentric and unsymmetrical load distribution in both inlet channels, two numbers of punches with a guided punch holder were used.

\section{Working Procedure to Join the Polymers}

Two polymer rods (working sample) from a commercially available Anulon-114 polyamide ([-NH-(CH2)5-CO]n MOS2) were prepared. Each polymer rod with a $0.1-\mathrm{mm}$ diametrical clearance was inserted inside an inlet channel and pressed by a $50-\mathrm{kN}$ universal testing machine (UTM) (Zwick/Roell Z005). The UTM has a given strain rate of $0.01 / \mathrm{s}$ and continues to press the rods until it reaches to $75 \%$ of billet length at room temperature as shown in Fig. 3. Polymer through cold die channel was not joined even at higher extrusion pressure. To join two similar natures of rods, polymer must pass through a preheated die. During the extrusion, it was ensured that the temperature of the preheated die did not exceed $/ 3$ of the polymer's melting point $\left(220^{\circ} \mathrm{C}\right)$. Softened polymers after crossing the trijunction entered into a common exit channel, hence polymer surfaces got diffused. The procedures were repeatedly performed to obtain defect-free joints (specimen-d), as shown in Fig. 4A. Line contact of two polymer rods, when passed through the reduced die section, caused arced interlocking along the transverse direction, resulting in the improvement in joint strength as shown in Fig. 4B. 


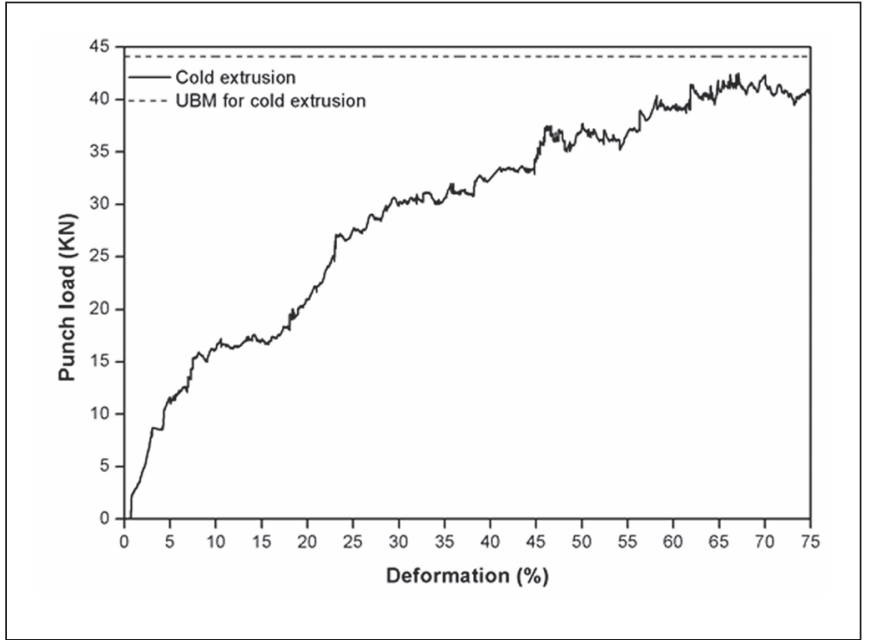

Fig. 5- Experimental and analytical extrusion load in cold die channel.

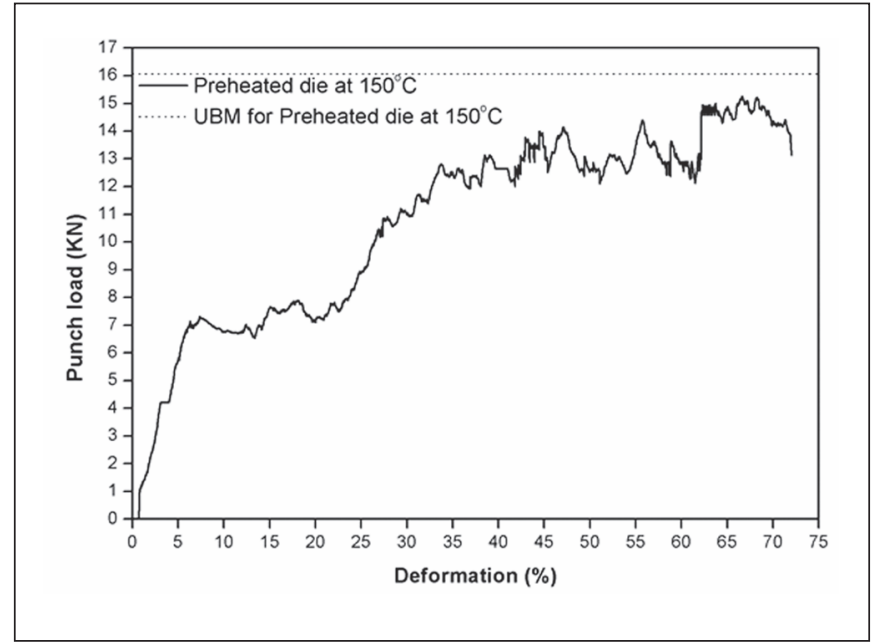

Fig. 6 - Experimental and UBM extrusion load in preheated die channel.

Table 1-Crystal Parameter of Anulon-114 Base and Joint Polymer

$\begin{array}{ccccc}\text { Sample } & \text { Crystal Form } & 2 \theta(\mathrm{deg}) & \mathrm{d}_{\text {hkl }}(\mathrm{nm}) & \mathrm{H}_{\text {hkl }}(\mathrm{nm}) \\ \text { Base Polymer } & \Upsilon & 14.1 & 0.627342 & 11.1662 \\ & \Upsilon & 16.9 & 0.523988 & 16.92034 \\ & \alpha & 18.62 & 0.475955 & 18.84516 \\ \text { Joint Polymer } & \Upsilon & 21.14 & 0.419756 & 16.27943 \\ & \Upsilon & 21.84 & 0.406461 & 13.44457 \\ & \alpha & 20 & 0.443293 & 4.577482 \\ & \alpha & 23.88 & 0.37216 & 3.06415\end{array}$

\section{Results}

\section{Punch Load in Y-Shape Extrusion Channel}

Actual punch load in an extrusion die is often very high and important from a safety point of view. The ultrasound biomicroscopy (UBM) technique gives a more appropriate approximate solution to determine the upper load of punch in an extrusion die. The energy required to perform plastic deformation based on UBM expression is given in Equation 2 (Ref. 26). After determining the kinematic admissible velocity field and using Equation 2, an analytical force model was developed in a circular Y-shape die channel, as given in Equation 3. To validate the analytical force model, experiments (cold and hot extrusion) were carried out to join two polymer rods through Yshape dies using UTM compression dies as shown in Fig. 3. The bottom part of the compression setup was stationary while the upper part was moving. Upper compression setup of UTM was in contact with two cylindrical punches having $11.90 \mathrm{~mm}$ diameter and 150-mm length to extrude the polymers. A guided punch holder was utilized to restrict free movement of both punch. Experimental punch load obtained for both cold and hot extrusion was then compared with the analytical model and is shown in Figs. 5 and 6.

$$
P=\int_{v} \sigma_{i j} \varepsilon_{1 J}^{\cdot} d V+\int_{s_{d}} \tau|\Delta u| d S=\int_{s_{t}} F_{i} u_{i}
$$

where $v$ is the workpiece volume, $\sigma_{\mathrm{ij}}$ is the stress tensor, $\varepsilon_{\mathrm{iJ}}$ is the strain rate tensor, $\mathrm{dV}$ is the differential volume, $\mathrm{s}_{\mathrm{d}}$ is surfaces discontinuity, $\tau$ is the shear stress, $|\Delta \mathrm{u}|$ is velocity discontinuity, $\mathrm{s}_{\mathrm{t}}$ is surface area of the workpiece, $\mathrm{F}_{\mathrm{i}}$ is the external force, $\mathrm{u}_{\mathrm{i}}$ is surface velocity, and $\mathrm{P}$ is the power in the deformation zone.

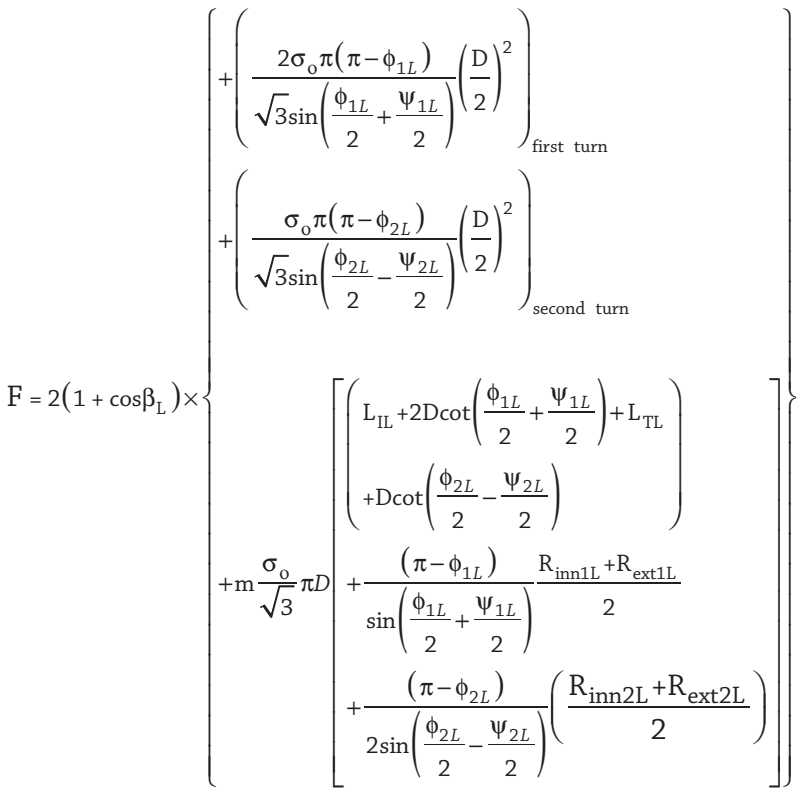

(3) 


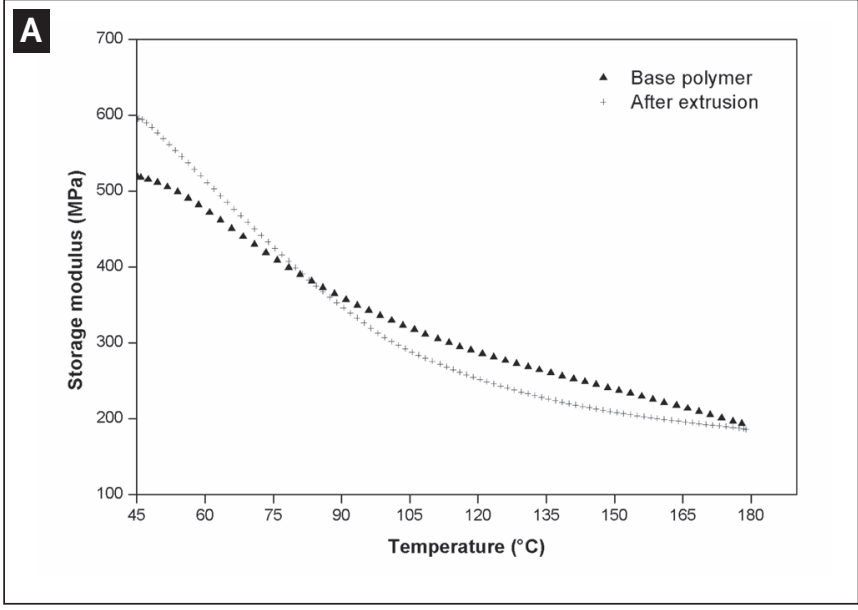

Fig. 7-A - Storage modulus; B - loss factor of polymer; $C-\tan \delta$ as a function of temperature.

where $\beta_{\mathrm{L}}$ is angle of left billet inclination with exit channel, $\sigma_{0}$ is flow stress determined from compression test, $\mathrm{D}$ is billet diameter, $\mathrm{m}$ is coefficient of friction, $\mathrm{L}_{1 \mathrm{~L}}$ is inlet length of billet in left ECAP channel, and $\mathrm{L}_{\mathrm{TL}}$ is taper length of billet in left ECAP channel. Other parameters are as defined in Fig. 2A.

\section{Dynamic Mechanical Analysis}

Dynamic mechanical analysis (DMA) of joint and base polymer was performed on a TA instrument analyzer in a singlecantilever mode with model DMA-Q800. Results were observed for storage modulus (E'), loss factor, and loss tangent $(\tan \delta)$ at a constant frequency of $1 \mathrm{~Hz}$ while varying the temperature from $45^{\circ}$ to $180^{\circ} \mathrm{C}$ with a heating rate of $5^{\circ} \mathrm{C} / \mathrm{min}$. A plot of storage modulus, loss factor, and tangent (loss factor/ storage modulus) with reference to variation in temperature for base and joint polymer are shown in Fig. 7A-C.

\section{X-Ray Diffractometer Analysis}

The DMA experiment was not suitable for the determination of crystal structure because every crystal has a different value of enthalpy, resulting in different crystalline formations. A nondestructive examination such as the $\mathrm{x}$-ray diffraction (XRD) was adapted for the crystalline behavior of Anulon-114 polymer. A polymer circular disc with $1 \mathrm{~mm}$ thickness and $12 \mathrm{~mm}$ diameter cut from base and joint polymer was prepared by following grinding and polishing processes. XRD of polymer disc was performed on the Rigaku model-TTRAX3 instrument with a supplying constant wavelength $(\lambda)$ of $0.1542 \mathrm{~nm}$. All peak intensities observed at different reflecting angles $(2 \theta)$ for both base and joint polymer are shown in Fig. 8A and B.

The crystals parameter (interplanar spacing and size) of base and joint polymer was determined by using Bragg's and Scherrer's relation as given in Equations 4 and 5 (Ref. 27) and presented in Table 1.

$$
\mathrm{d}_{\mathrm{hkl}}=\frac{\lambda}{2 \sin \theta}
$$
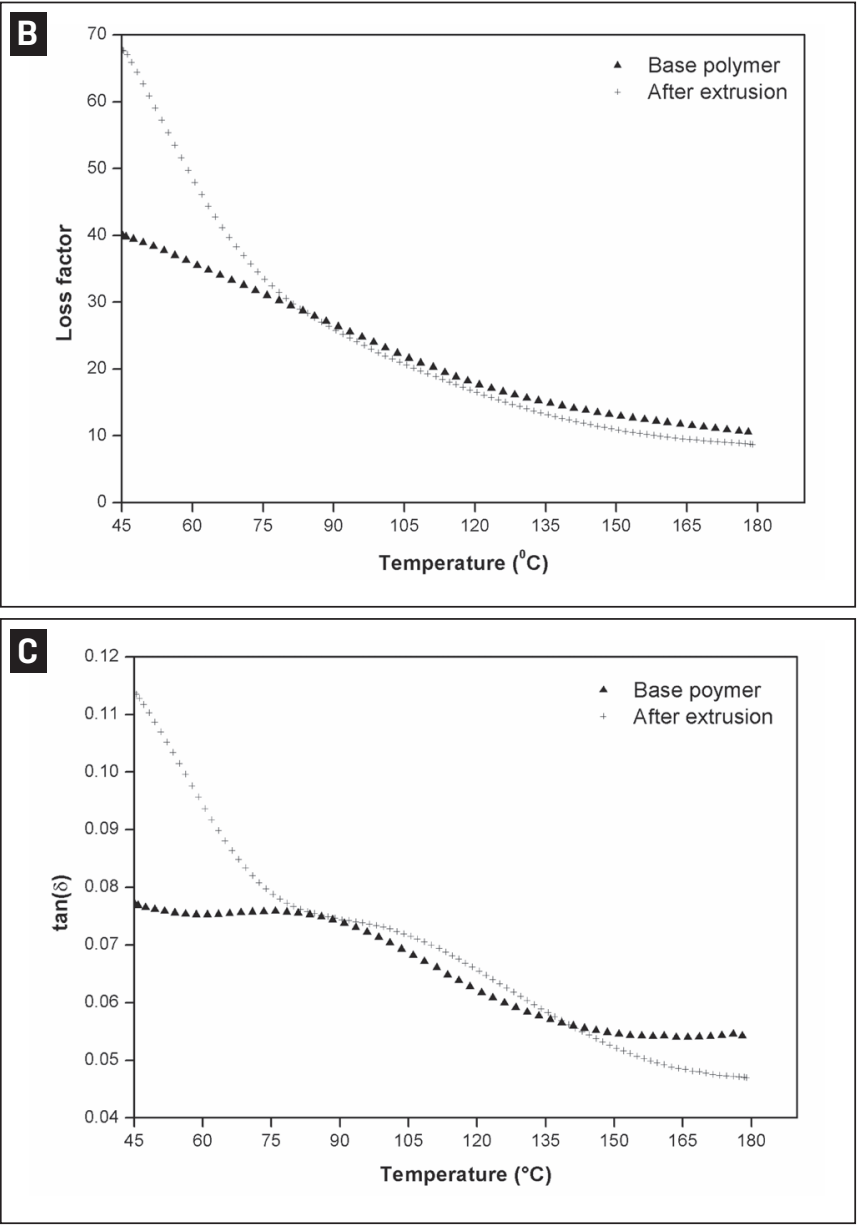

where $d_{\text {hkl }}$ is the interplaner distance of crystallite, $\lambda$ $(0.154056 \mathrm{~nm})$ is the wavelength of $\mathrm{x}$-ray, and $\theta$ is the incident angle.

$$
\mathrm{H}_{\mathrm{hkl}}=\frac{\mathrm{K} \lambda}{\sqrt{\mathrm{w}^{2}-\mathrm{b}^{2}} \frac{\pi}{180} \cos \theta}
$$

where $\mathrm{H}_{\text {hkl }}$ is the crystallite size, hkl is the miller indices, $\mathrm{k}(0.89)$ is the shape factor of crystallite, $\mathrm{w}$ is the half diffraction peak width, and $b(0.15)$ is the broaden factor of the apparatus.

\section{Discussion}

\section{Punch Load in Y-Shape Extrusion Channel}

In cold extrusion, it is observed that the polymer rod extruded from the die exit channel is not joined, and corresponding punch loads are recorded as shown in Fig. 5. The load required to compress the billet in the inlet channel increased rapidly until it completely filled the gap of the first die turn while achieving a punch load up to $8 \mathrm{kN}$. A constant punch load of $27 \mathrm{kN}$ was achieved when polymer began to flow through a 25-mm-long taper channel and suddenly increased when it reached the second turn. When the billet reached the end of the second die turn, it exerted back pressure over another polymer, resulting in the accumulation of 


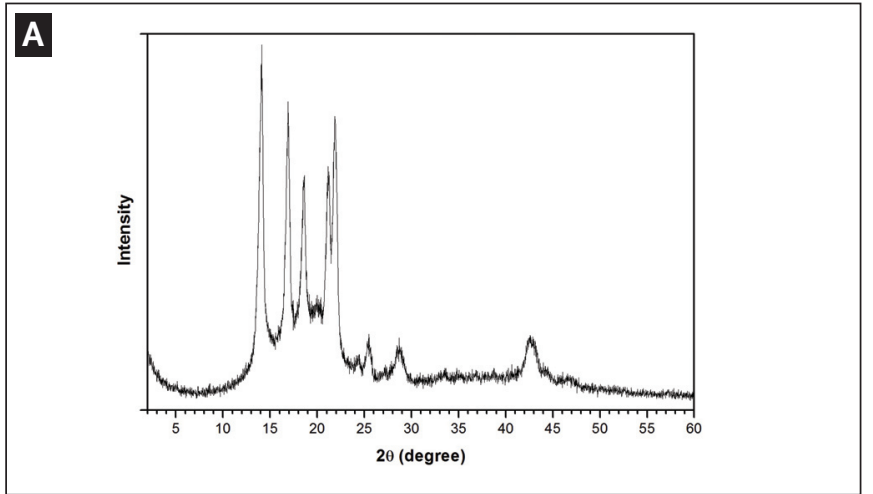

Fig. 8 - XRD pattern: A - Base polymer; B - joint polymer.

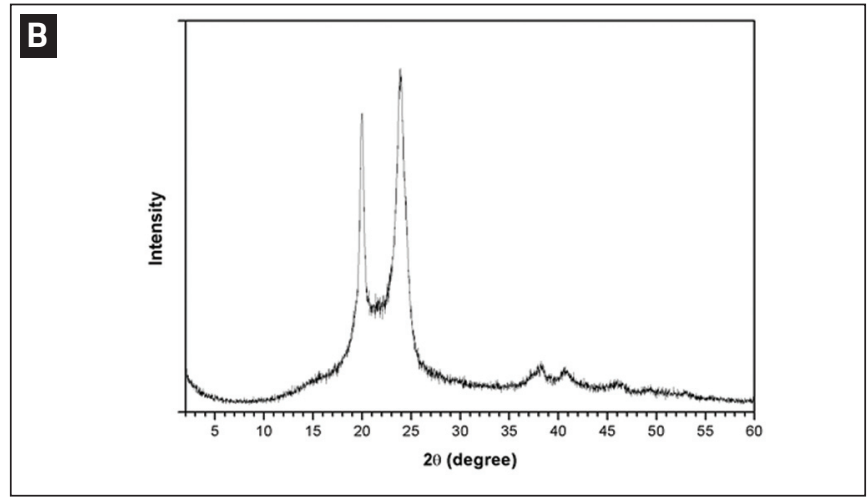

material at tri-junction. Upon continuous application of load, material began to flow through the die common exit channel at a constant punch load of $43 \mathrm{kN}$. The material employed for cold extrusion has a flow stress of $47 \mathrm{MPa}$, resulting in $44.1 \mathrm{kN}$ of analytical load, which is $2.5 \%$ higher than experimental load.

To join the polymers, preheated die channel (at $150^{\circ} \mathrm{C}$ ) was utilized and the corresponding punch load is recorded as shown in Fig. 6. Load experienced in the preheated die channel was much lower than cold die channel. Up to first turn, the punch load rapidly increased to $7.5 \mathrm{kN}$ and almost constant in die taper channel. Developed back pressure at tri-junction caused the punch load to increase up to $15 \mathrm{kN}$, which is much lower compared to cold extrusion. The material employed for hot extrusion has flow stress of $13 \mathrm{MPa}$, resulting in $16.1 \mathrm{kN}$ of analytical load, which is $6.8 \%$ higher than the experimental load.

\section{Dynamic Mechanical Analysis}

Below the glass transition temperature, segmental mobility in joint polymer is highly restricted due to which storage modulus is higher as compared to the base polymer observed in Fig. 7A. Increase in temperature softens the polymers, resulting in a decrease in storage modulus. Due to the low viscoelastic nature of joint polymer, the rate of crystal debonding is higher, resulting in a lower storage modulus as compared to base polymer. A sharp and slight decrease of E' for both joint and base polymer finally became equals at $78^{\circ} \mathrm{C}$; thereafter, both polymers slightly decreased and reached a constant storage modulus at $180^{\circ} \mathrm{C}$. When temperature is at $45^{\circ} \mathrm{C}$, joint polymer has $15 \%$ higher storage modulus as compared to base polymer. Polymer processed through the preheated die channel shows $67.5 \%$ higher loss factor as compared to base polymer due to loss of energy in the form of heat as shown in Fig. 7B. At a higher temperature from $78^{\circ}$ to $180^{\circ} \mathrm{C}$, the loss factor of the bases polymer become higher than the joint polymer due to segmentation of the polymer chain. It is observed from Fig. $7 \mathrm{C}$ that the base polymer has two different glass transition temperatures $\left(45^{\circ}\right.$ and $\left.88^{\circ} \mathrm{C}\right)$, which is due to molecular motion of polymer chain. Similarly, glass transition temperature of joint polymer is observed at $45^{\circ}$ and $96^{\circ} \mathrm{C}$. The maximum $\tan \delta$ for base and joint polymer is approximately 0.078 and 0.114 , respectively. Higher $\tan \delta(31 \%)$ in joint polymer is an indication of low elasticity and high storage modulus due to die preheating.

\section{X-Ray Diffractometer Analysis}

Polymers' mechanical properties are completely bounded with their crystalline stability in the form of hydrogen bonding. The presence of hydrogen bonding in parallel and antiparallel chain arrangement is referred to $\alpha$-form and ' $\Upsilon$ form stability of polymers (Ref. 28). All peak intensities about $2 \theta$ at $14.1,16.9,21.14$, and 21.84 deg are characterized as ' $\Upsilon$-form and $18.62 \mathrm{deg}$ as $\alpha$-form stability of base polymer as observed from Fig. 8A (Ref. 29). Position of peak intensities at 20 and $20.88 \mathrm{deg}$ are characterized as $\alpha$-form stability of polymers when processed through preheated die as observed from Fig. 8B (Ref. 30). It is also observed that peak positions $(2 \theta)$ of joint polymers have been shifted as compared to base polymer, which is due to joint interference. Similarly, lower shoulder width is an indication of higher crystallinity as observed in joint polymer. Fusion heat due to the presence of ' $\Upsilon$-form in base polymer makes a stronger interaction between the polymers' chain by converting into $\alpha$-form. The disappearance of ${ }^{\prime} \Upsilon$-form in a joint polymer caused by Brill transition when two reflection peaks merged into a single $\alpha$-form (Refs. 31,32 ) is an indication of an increase in bond strength as compared to base polymer. The developed $\alpha$-form is the most thermally stable crystalline form of Anulon-114 polymer. It is observed from Table 1 that antiparallel chain arrangement is transformed to parallel chain arrangement indicated by a significant reduction of interplanar distance $\left(d_{\mathrm{hkl}}\right)$ when polymer blended through the Y-shape die channel. Irregular value of crystallite size $\left(\mathrm{H}_{\mathrm{hkl}}\right)$ of base polymer is an indication of inhomogeneous dispersion. Inhomogeneity of joint polymer significantly reduces as compared to base polymer. Pressure and fusion heat through ECAP-based Y-shape channel causes the refinement of crystal size, hence, polymers crystallinity increases.

\section{Conclusions}

This paper demonstrated the weldability of polymer through SPD-based Y-shape die. This study was completed by considering the all-geometrical parameters of ECAP channel. Polymer processed through preheated die channel required 
$65 \%$ lower punch load as compared to cold die channel. Even though loss of energy is more and plasticity reduces significantly in case of joint polymer, it achieved $15 \%$ higher storage modulus as compared to base polymer at $45^{\circ} \mathrm{C}$ as evidenced by the DMA analysis. Reduced crystallite size and interplaner distance with homogeneous dispersion in joint polymer is evidenced from the XRD analysis. A proposed design configuration of preheated Y-shape die transforms the $\Upsilon$-form into $\alpha$ form stability of blended polymers.

\section{References}

1. Ostwald, P. F., and Munoz, J. 2008. Manufacturing Processes and Systems. John Wiley \& Sons.

2. Gupta, N., and Paramsothy, M. 2014. Metal- and polymermatrix composites: Functional lightweight materials for highperformance structures. JOM 66(6): 862-865. DOI: 10.1007/ s11837-014-0969-0

3. Das, S. 2001. The cost of automotive polymer composites: A review and assessment of DOE's lightweight materials composites research (No. ORNL/TM-2000/283). Oak Ridge National Lab, Tenn.

4. Tamrin, K. F., Yusoff, N., and Zakariyah, S. S. 2013. Laser lap joining of dissimilar materials: A review of factors affecting joint strength. Materials and Manufacturing Processes 28(8): 857-871. DOI: $10.1080 / 10426914.2013 .792413$

5. Zhao, H., Fu, Z., Wu, Y. X., and Zhao, Y. Z. 2007. Design and implementation of an auto bonding manufacturing process for space solar cells. Materials and Manufacturing Processes 22: 851-858. DOI: 10.1080/10426910701448909

6. Grewell, D., and Benatar, A. 2007. Welding of plastics: Fundamentals and new developments. International Polymer Processing 22(1): 43-60. DOI: doi.org/10.3139/217.0051

7. Meschut, G., Janzen, V., and Olfermann, T. J. 2014. Innovative and highly productive joining technologies for multi-material lightweight car body structures. Journal of Materials Engineering and Performance 23(5): 1515-1523. DOI: 10.1007/s11665-0140962-3

8. Kah, P., Suoranta, R., Martikainen, J., and Magnus, C. 2014. Techniques for joining dissimilar materials: Metals and polymers. Review on Advanced Materials Science 36: 152-164.

9. Bartczak, B., Mucha, J., and Trzepieciński, T. 2013. Stress distribution in adhesively-bonded joints and the loading capacity of hybrid joints of car body steels for the automotive industry. International Journal of Adhesion and Adhesives 45: 42-52. DOI: 10.1016/j.ijadhadh.2013.03.012

10. Yousefpour, A., Hojjati, M., and Immarigeon, J. 2004. Fusion bonding/welding of thermoplastic composites. Journal of Thermoplastic Composite Materials 17(4): 303-341. DOI: 10.1177/ 0892705704045187

11. Dilip, J. J. S., Babu, S., Varadha Rajan, S., Rafi, K. H., Janaki Ram, G. D., and Stucker, B. E. 2013. Use of friction surfacing for additive manufacturing. Materials and Manufacturing Processes 28(2): 189-194. DOI: 10.1080/10426914.2012.677912

12. Ojeda, T. 2013. Polymers and the Environment. In Polymer Science InTech. DOI: 10.5772/51057

13. Nelson, T. W., Sorenson, C. D., and Johns, C. J. 2004. Friction Stir Welding of Polymeric Materials. U.S. Patent No. 6,811,632. Washington, D.C.: U.S. Patent and Trademark Office.

14. Bozkurt, Y. 2012. The optimization of friction stir welding process parameters to achieve maximum tensile strength in polyethylene sheets. Materials \& Design 35: 440-445. DOI: 10.1016/ j.matdes.2011.09.008

15. Kumar, P., and Panda, S. S. 2018. An innovative method to join two polymer rods through Y-shape extrusion channel. Measurement 119: 270-282. DOI: 10.1016/j.measurement.2018.01.060
16. Segal, V. M. 1977. The Method of Material Preparation for Subsequent Working. Patent of the USSR. No. 575892.

17. Kumar, P., and Panda, S. S. 2017. Finite element analysis of die offset in two-turn incremental ECAP. Materials Today: Proceedings 4(2): 2419-2424. DOI: 10.1016/j.matpr.2017.02.092

18. Kumar, P., and Panda, S. S. 2018. A review on properties and microstructure of micro-extruded product using SPD and as-cast material. Sädhanā 43(5): 77. DOI: 10.1007/s12046-018-0874-2

19. Surendarnath, S., Sankaranarayanasamy, K., and Ravisankar, B. 2014. Workability study on $99.04 \%$ pure aluminum processed by ECAP. Materials and Manufacturing Processes 29: 691-696. DOI: 10.1080/10426914.2014.892978

20. Bhupatiraju, M., and Greczanik, R. 2013. Cold extrusion. ASM Handbook, Volume 14A: Metalworking: Bulk Forming. S. L. Semiatin (Ed.). 405-418.

21. Wang, Y. L., Lapovok, R., Wang, J. T., Qi, Y. S., and Estrin, Y. 2015. Thermal behavior of copper processed by ECAP with and without back pressure. Materials Science and Engineering: A 628: 21-29. DOI: 10.1016/j.msea.2015.01.021

22. Kumar, P., and Panda, S. S. 2017. Numerical simulation of Al1070 alloy through hybrid SPD process. The International Journal of Advanced Manufacturing Technology 91(1-4): 835-846. DOI: 10.1007/s00170-016-9768-9

23. Murthy, N. S., Curran, S. A., Aharoni, S. M., and Minor, H. 1991. Premelting crystalline relaxations and phase transitions in nylon 6 and 6,6. Macromolecules 24(11): 3215-3220.

24. Paul, D. R., and Robeson, L. M. 2008. Polymer nanotechnology: Nanocomposites. Polymer 49(15): 3187-3204. DOI: 10.1016/ j.polymer.2008.04.017

25. Kumar, P., and Panda, S. S. 2018. A Method of Joining Polymers Rods Through Deformation Technique Using a Y-Shape Die Apparatus. Indian Institute of Technology Patna. Indian Patent Reference No. 201831007503.

26. Kobayashi, S., Kobayashi, S., Oh, S. I., and Altan, T. 1989. Metal Forming and the Finite Element Method. Oxford University Press on Demand.

27. Shan, G. F., Yang, W., Xie, B. H., Li, Z. M., Chen, J., and Yang, M. B. 2005. Double yielding behaviors of polyamide 6 and glass bead filled polyamide 6 composites. Polymer Testing 24(6): 704-711. DOI: 10.1016/j.polymertesting.2005.05.003

28. Jahromi, A. E., Jahromi, H. R. E., Hemmati, F., Saeb, M. R., Goodarzi, V., and Formela, K. 2016. Morphology and mechanical properties of polyamide/clay nanocomposites toughened with NBR/NBR-g-GMA: A comparative study. Composites Part B: Engineering 90: 478-484. DOI: 10.1016/j.compositesb.2015.12.042

29. Fornes, T. D., and Paul, D. R. 2003. Crystallization behavior of nylon 6 nanocomposites. Polymer 44(14): 3945-3961. DOI: 10.1016/S0032-3861(03)00344-6

30. Pan, B., Yue, Q., Ren, J., Wang, H., Jian, L., Zhang, J., and Yang, S. A. 2006. A study on attapulgite reinforced PA6 composites. Polymer Testing 25(3): 384-391. DOI: 10.1016/j.polymertesting.2005.11.012

31. Murthy, N. S., Aharoni, S. M., and Szollosi, A. B. 1985. Stability of the $\gamma$ form and the development of the $\alpha$ form in nylon 6 . Journal of Polymer Science Part B: Polymer Physics 23(12):

2549-2565. DOI: 10.1002/pol.1985.180231212

32. Kyotani, M., and Mitsuhashi, S. 1972. Studies on crystalline forms of nylon 6. II. Crystallization from the melt. Journal of Polymer Science Part B: Polymer Physics 10(8): 1497-1508. DOI: 10.1002/pol.1972.160100807

PINTU KUMAR (pintu.pmel3@iitp.ac.in) and SUDHANSU SEKHAR PANDA (sspanda@iitp.ac.in) are with the Department of Mechanical Engineering, Indian Institute of Technology Patna, Bihar, India. 